\title{
None Operational Amplifier (OPA) Based: Design of Analogous Bandgap Reference Voltage
}

\author{
Hao-Ping Chan and Yu-Cherng Hung* \\ Department of Electronic Engineering, National Chin-Yi University of Technology, Taiwan (ROC)
}

\begin{abstract}
By using 0.35-um CMOS process, this work achieves a design of analogous band-gap reference voltage circuit with low temperature coefficient. The proposed circuit operates at $3 \mathrm{~V}$ and generates a reference current of $44 \mathrm{uA}$. The HSPICE simulation results show the temperature coefficient of this circuit is $23 \mathrm{ppm} /{ }^{\circ} \mathrm{C}$ at range of $-10{ }^{\circ} \mathrm{C}$ to $100{ }^{\circ} \mathrm{C}$, and the line regulation (the ratio of output current variation to supply voltage variation) is estimated as $1.95 \mathrm{uA} / \mathrm{V}$ from supply voltage variation of $3 \mathrm{~V}$ to $5 \mathrm{~V}$. The experimental chip is fabricated and measured. The circuit provides adjustable capability for output voltage among temperature variation of $-10-100{ }^{\circ} \mathrm{C}$. The chip area is $534 \times 695 \mathrm{um}^{2}$. In this new design, the operational amplifier is not necessary. The chip design effort can be great reduced.
\end{abstract}

\section{Introduction}

Because of the convenience and portability, more portable consumer electronic devices are frequently used today. There are always tens to hundreds of chips cooperation within these consumer electronic devices. In order to further shrink device size and toward lightweight continuously, more electronic elements are expected to be integrated into a chip to realize the system almost functions. As a result, the function of chip trends towards from single specific to system multiple functions. In general, a system-embedded-on-a-chip (SoC) has multiple voltage sources or voltage references within chip design. The capability of voltage reference is with low output voltage/current variation in spite of variety of temperature, supply voltage, and noise interfered. Therefore, the voltage reference circuit currently has been widely used in analog circuit, digital circuit and mixed-signal circuit, such as operational amplifiers, analog-to-digital converters (ADC), digitalto-analog converters (DAC), phase locked loop (PLL) circuits and power regulators. In open literature, many circuit schemes for voltage reference and its improved versions have been proposed [1-8] in recent years. The performance of voltage reference will dominate the system function. The design of internal voltage reference circuit becomes more important especially for in SoC era. Currently, the most popular circuit scheme is bandgap voltage reference.

The basic circuit for bandgap voltage reference is shown in Fig. 1. The bootstrapping circuit makes the potential voltage of nodes ' $a$ ' and node ' $b$ ' as equal as possible, to reduce the effects of channel length modulation and supply voltage variation. It uses emitterbase voltage difference between two bipolar junction transistors (BJTs) to generate a positive temperature coefficient (PTC) current. In conventional CMOS technologies, these BJTs are parasitic transistors. After that, it uses current mirror architecture (M3/M4/M5) to copy the PTC current to the output resistor $\mathrm{R}_{\mathrm{L}}$. The voltage drop $V_{\mathrm{RL}}$ is added to $V_{\mathrm{EB}}$ of $\mathrm{BJT}$ with negative temperature coefficient to generate a stable reference voltage output. Finally, the objective of the basic circuit is to form a precise and stable voltage reference in spite of temperature variations and supply voltage fluctuations. The output of bandgap reference circuit shown in Fig. 1 is given as

$$
V_{\text {ref }}=V_{E B}+\Delta V_{E B}\left(\frac{R_{L}}{R_{1}}\right)
$$

$V_{\mathrm{EB}}$ is with negative temperature coefficient, and $\Delta V_{E B}$ related to thermal voltage $V \mathrm{t}$ (that is, $k \mathrm{~T} / \mathrm{q}$ ) is with positive temperature coefficient. The temperature effects of $V_{\mathrm{EB}}$ and $\Delta V_{E B}$ are about $-2.5 \mathrm{mV}$ and $+0.085 \mathrm{mV}$ per centigrade degree respectively. According to the proper ratio settings of $R_{L}, R_{1}$, and the area matching in BJTs, temperature effect of output voltage can be canceled drift out each other. Therefore, output $V_{\text {ref }}$ in theoretically can be obtained in independent of temperature.

However, the voltage on nodes ' $a$ ' and ' $b$ ' in Fig. 1 is not identical potential due to the channel length modulation and body effects. The temperature coefficient of basic scheme is a little bit large. Another conventional bandgap reference voltage circuit is shown in Fig.2. An operational amplifier is embedded in the circuit to provide nearly equal voltage between two input nodes. The output voltage of bandgap reference circuit is also given as Eq. 1. In despite of Figs. 1 and 2, the ratio of $R_{L}$ and $R_{1}$ is always to set a proper value to keep the output voltage temperature insensitivity.

\footnotetext{
Corresponding author: ychung@ncut.edu.tw
} 


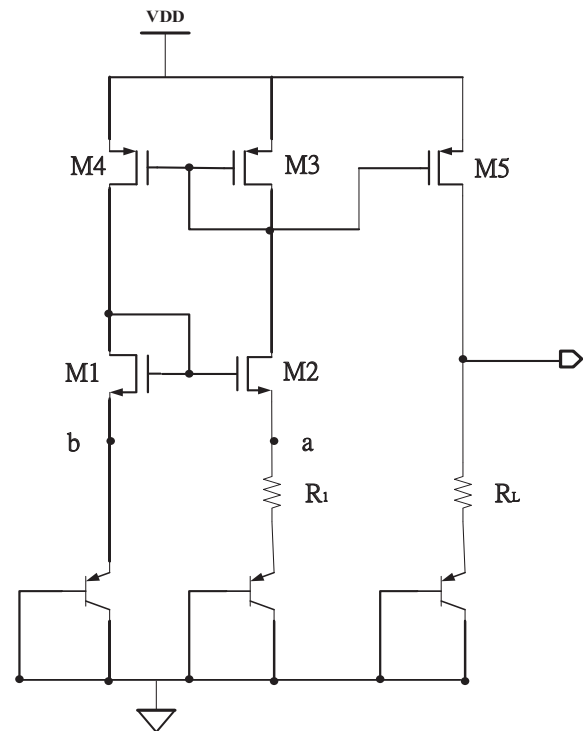

Fig. 1. Basic bandgap reference voltage circuit.

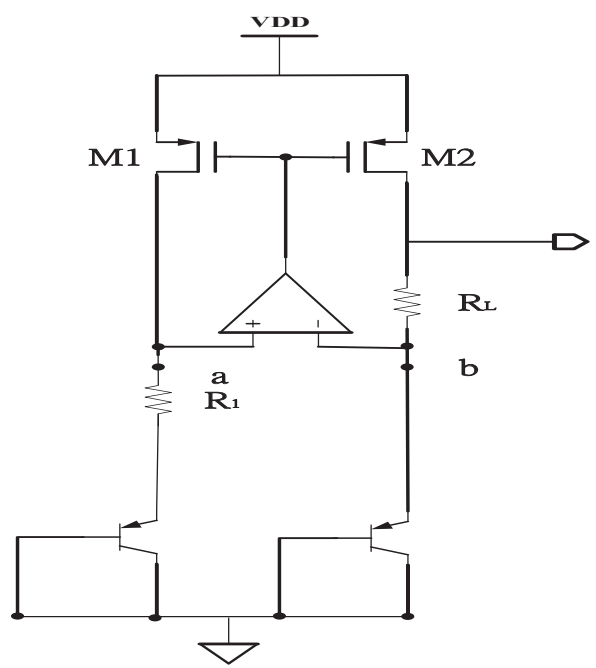

Fig. 2. Another basic bandgap reference voltage circuit (with opa)

Based on Fig. 2 scheme, an improved circuit for output voltage adjustable is achieved as Fig. 3 [1]. The circuit makes the output reference voltage can be altered by using various resistors ratios. In contrasting to Fig. 2, an additional operational amplifier and current mirror are extra used in Fig. 3. Due to high-gain operational amplifier, voltage on nodes ' $b$ ' and ' $c$ ' are equal. The current of $\mathrm{M} 3$ is $\mathrm{V}_{\mathrm{EB}} / \mathrm{R}_{2}$ with negative temperature coefficient. By M3/M4 current mirror, the current of M4 is $\left(\mathrm{V}_{\mathrm{EB}} / \mathrm{R}_{2}\right)(\mathrm{W} / \mathrm{L})_{\mathrm{M} 4} /(\mathrm{W} / \mathrm{L})_{\mathrm{M} 3}$. After M4/M5 current summation, the voltage of the output resistor $\mathrm{R}_{\mathrm{L}}$ can be derived as

$V_{r e f}=R_{L}\left(\frac{V_{E B}}{R_{2}} \frac{(W / L)_{M 4}}{(W / L)_{M 3}}+\frac{\Delta V_{E B}}{R_{1}} \frac{(W / L)_{M 5}}{(W / L)_{M 2}}\right)$.

The desired output voltage Vref can be obtained by settings of various resistances and aspect ratio of transistors. However, two operational amplifiers are needed in this design. In general, the design of operational amplifier with high performance in chip realization is difficult by using conventional process.

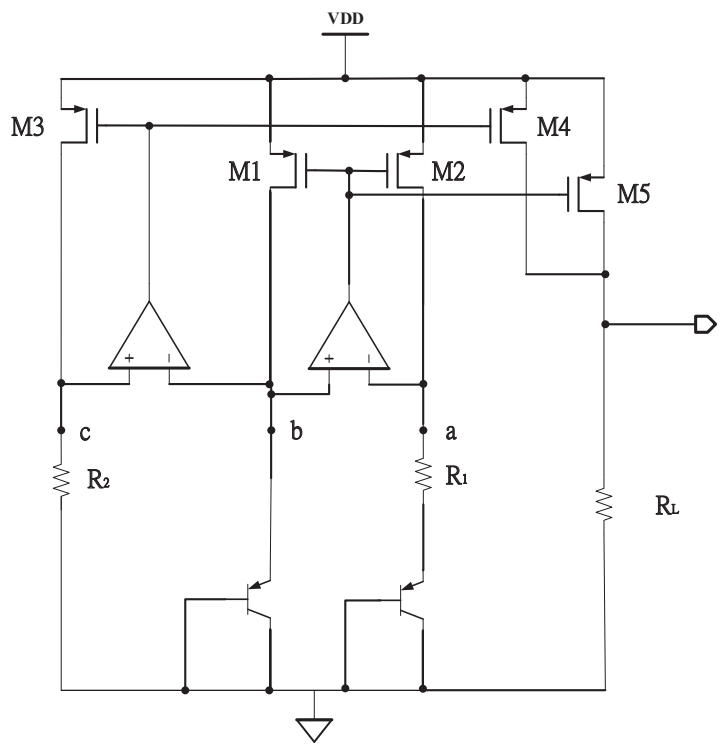

Fig. 3. The bandgap reference voltage with adjustable capability [1].

\section{Circuit Design}

In consideration of the following two issues: first, the output voltage of conventional band-gap reference circuit is always limited to around $1.25 \mathrm{~V}$, due to the constant ratio of negative temperature coefficient of $\mathrm{V}_{\mathrm{EB}}$ and positive temperature coefficient of $\Delta \mathrm{V}_{\mathrm{EB}}$. The second issue, a high performance operational amplifier is not easily realized in chip. In addition, the overall circuit complexity and power consumption are resulted in increased due to these more electronic elements. In this study, bandgap reference voltage circuit without needing operational amplifier is redesigned and inspected. The new schematic diagram of the circuit is shown in Fig. 4.

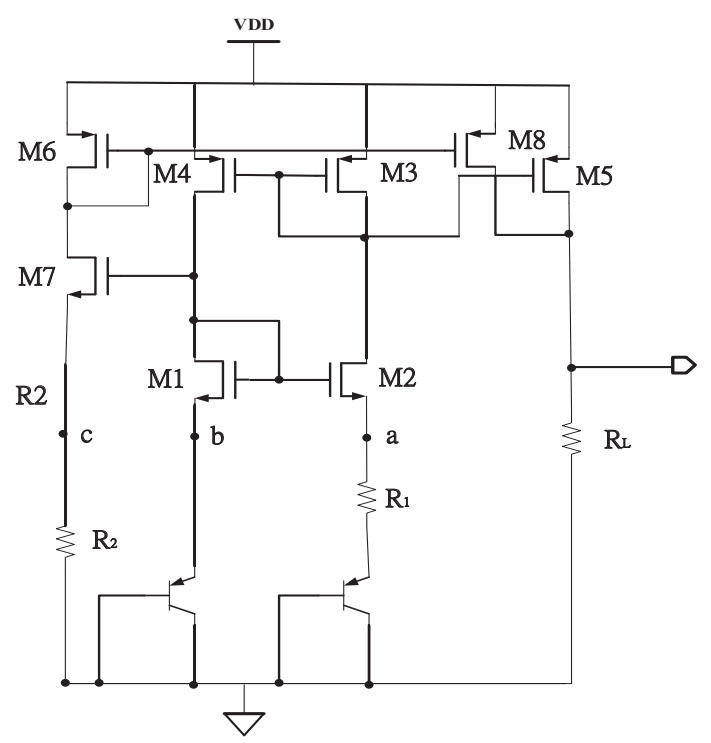

Fig. 4. The proposed bandgap reference voltage circuit without needing of operational amplifier. 
The current mirror function is achieved by M1/M4/M6/M7 to make nodes ' $b$ ' and 'c' voltage as equipotential as possible. Due to the equipotential, the current flows through resistor $\mathrm{R}_{2}, I_{\mathrm{R} 2}=\mathrm{V}_{\mathrm{EB}} / \mathrm{R}_{2}$, which is a negative temperature coefficient current. The current mirror of M6 and M8 is used to copy the current and addition of the positive temperature coefficient current $I_{\mathrm{M} 5}$. Finally, the output current with nearly zero temperature coefficient will be expected to arrive. The expression of the bandgap reference voltage is given as

$$
V_{r e f}=R_{L}\left(\frac{V_{E B}}{R_{2}} \frac{(W / L)_{M s}}{(W / L)_{M 6}}+\frac{\Delta V_{E B}}{R_{1}} \frac{(W / L)_{M 5}}{(W / L)_{M 3}}\right) .
$$

A start-up circuit is needed to avoid a zero output current (another stable bias point) held in circuit initial phase. The whole circuit including start-up circuit is shown in Fig. 5. Transistors M9-M11 try to achieve a none zero current $I_{\mathrm{D}}$ in transistors M1 and M2 when the circuit is initially powered up.

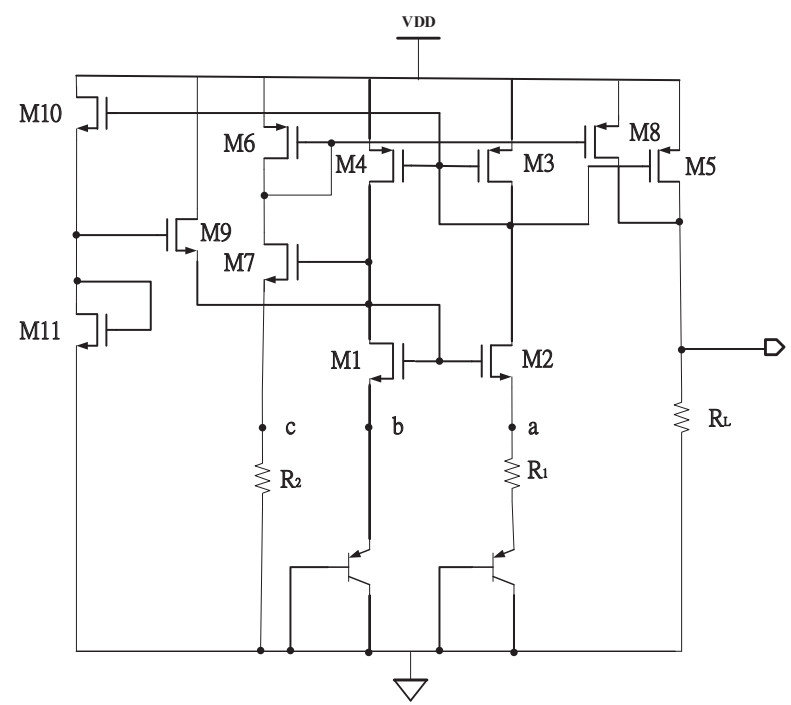

Fig. 5. The whole proposed bandgap reference voltage circuit.

\section{Simulation and Chip Measured Results}

Based on TSMC 0.35- $\mu \mathrm{m}$ CMOS process, the whole circuit shown in Fig. 5 is simulated by using HSPICE simulation program. HSPICE is a very popular circuit simulator in chip design, and nearly it is a de facto standard to verify circuit function. Figures 6 to 13 show the simulation results. Figure 6 shows the line regulation of output current when supply voltage varies from $3 \mathrm{~V}$ to $5 \mathrm{~V}$. In Fig. 6 , the output current of the circuit is $44.8 \mu \mathrm{A}$ at $3-\mathrm{V}$ supply voltage and $48.7 \mu \mathrm{A}$ at $5 \mathrm{~V}$. The line regulation for output current is estimated as $1.95 \mu \mathrm{A} / \mathrm{V}$.

Another important factor for bandgap reference: temperature coefficient will be inspected. When the loading is altered and varied, the circuit is still function works within reasonable low temperature coefficients. We use various loading resistances of $1 \Omega, 10 \Omega, 100$ $\Omega, 1 \mathrm{k} \Omega, 10 \mathrm{k} \Omega, 20 \mathrm{k} \Omega$ and $30 \mathrm{k} \Omega$ to inspect the output voltage variation when temperature is varied from -10
${ }^{\circ} \mathrm{C}$ to $100{ }^{\circ} \mathrm{C}$. Under $\mathrm{R}_{\mathrm{L}}$ loading of $1-\Omega$, Fig. 7 shows the output voltage variation in temperature of $-10{ }^{\circ} \mathrm{C}$ to 100 ${ }^{\circ} \mathrm{C}$. The maximum output reference voltage is $44.841 \mu \mathrm{V}$ and the minimum output reference voltage is $44.728 \mu \mathrm{V}$. The temperature coefficient (TC) of the circuit for output voltage is evaluated as $23 \mathrm{ppm} /{ }^{\circ} \mathrm{C}$.

In $R_{L}$ loading of $10-\Omega$, Fig. 8 shows the maximum output reference voltage $448.411 \mu \mathrm{V}$ and minimum reference voltage $447.276 \mu \mathrm{V}$. The TC also keeps 23 $\mathrm{ppm} /{ }^{\circ} \mathrm{C}$. Figs. $9-13$ show the TC variations for loading resistances in $100 \Omega, 1 \mathrm{k} \Omega, 10 \mathrm{k} \Omega, 20 \mathrm{k} \Omega$ and $30 \mathrm{k} \Omega$ respectively. In Fig. 9, the maximum reference voltage is $4.484 \mathrm{mV}$ and the minimum reference voltage is 4.473 $\mathrm{mV}$. In Fig. 10, the maximum reference voltage is $44.827 \mathrm{mV}$ and the minimum reference voltage is 44.714 $\mathrm{mV}$. In Fig. 11, the maximum reference voltage is $446.957 \mathrm{mV}$ and the minimum reference voltage is $445.850 \mathrm{mV}$. In Fig. 12, the maximum reference voltage is $892.618 \mathrm{mV}$ and the minimum reference voltage is $890.172 \mathrm{mV}$. In Fig. 13, the maximum reference voltage is $1.33 \mathrm{~V}$ and the minimum reference voltage is $1.3266 \mathrm{~V}$. Obviously, Figs.7-13 shows the TC of the voltage reference almost keeps on $23 \mathrm{ppm} /{ }^{\circ} \mathrm{C}$ in range of loading resistance of $1 \Omega$ to $30 \mathrm{k} \Omega$. Finally, according to these data, Fig. 14 shows the corresponding TC value.

The layout diagram and micro-photo of proposed circuit is shown in the top part and bottom part of Fig. 15 respectively, and the chip area is $534.55 \times 694.85 \mathrm{um}^{2}$. After layout phase, the parasitic effects are also extracted. The post-layout simulation in loading $R_{L}$ of $1-\Omega$ is shown in Fig. 16. Since the effects of parasitic resistance and capacitance, the TC of the reference voltage is raised from 23 to $26 \mathrm{ppm} /{ }^{\circ} \mathrm{C}$. The chip fabrication is achieved already. The micro-photo of the chip is shown in right part of Fig. 15. When under temperature $25{ }^{\circ} \mathrm{C}$ and loading $\mathrm{R}_{\mathrm{L}} 27 \mathrm{k} \Omega$, the output of the voltage reference is $1.07 \mathrm{~V}(39.629 \mathrm{uA} \times 27 \mathrm{k})$ for $3-\mathrm{V}$ supply voltage and $1.12 \mathrm{~V}(41.48 \mathrm{uA} \times 27 \mathrm{k})$ for $5-\mathrm{V}$ supply voltage. The digital oscilloscope (TBS1052B-EDU) by Tektronix is used to measure the experimental chip for output voltage. Figures 17 (a) and (b) show the measured results for $3-\mathrm{V}$ and 5-V supply voltage respectively. In addition, when temperature on the surface of the chip is risen to $100{ }^{\circ} \mathrm{C}$, the variation of output voltage is not revealed by using the digital oscilloscope due to 3\% measurement accuracy of this instrument.

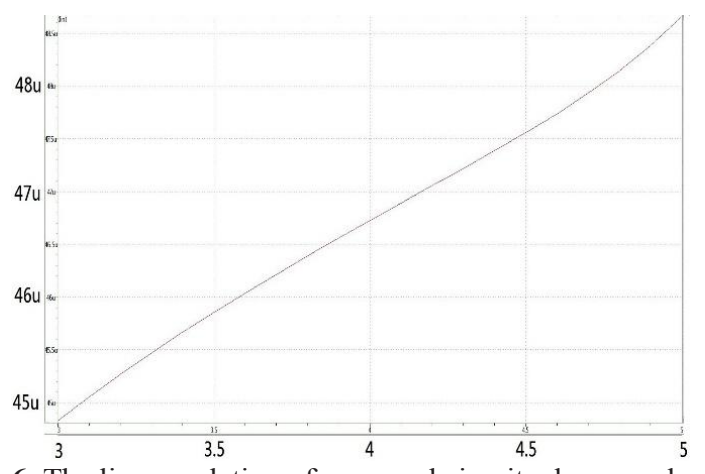

Fig. 6. The line regulation of proposed circuit when supply voltage varied from 3 to $5 \mathrm{~V}$. 


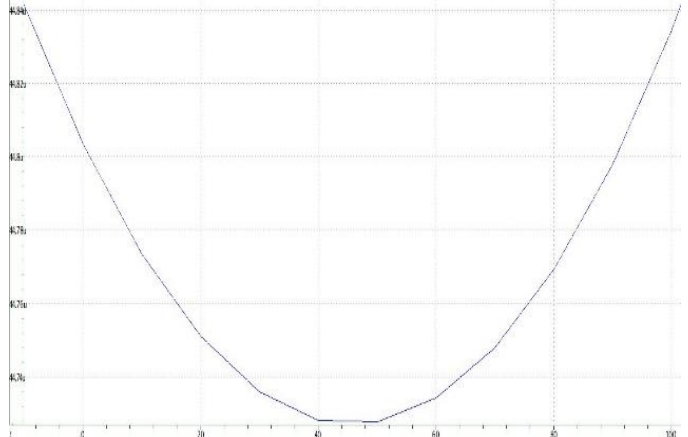

Fig. 7. The temperature coefficient of output current in loading resistance of $1 \Omega$.

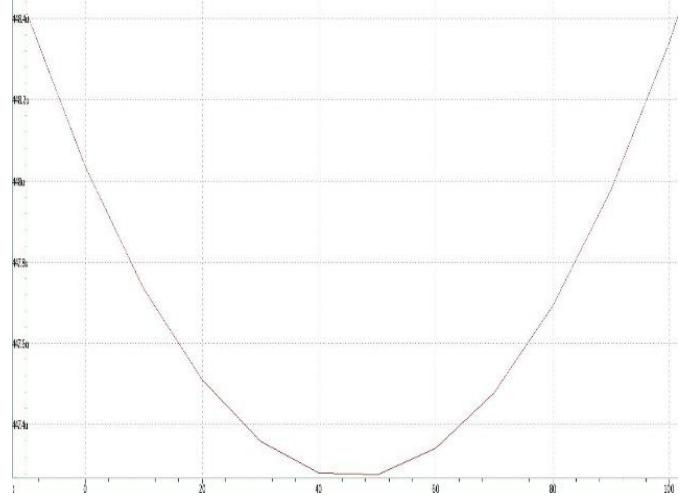

Fig. 8. The temperature coefficient of output current in loading resistance of $10 \Omega$.

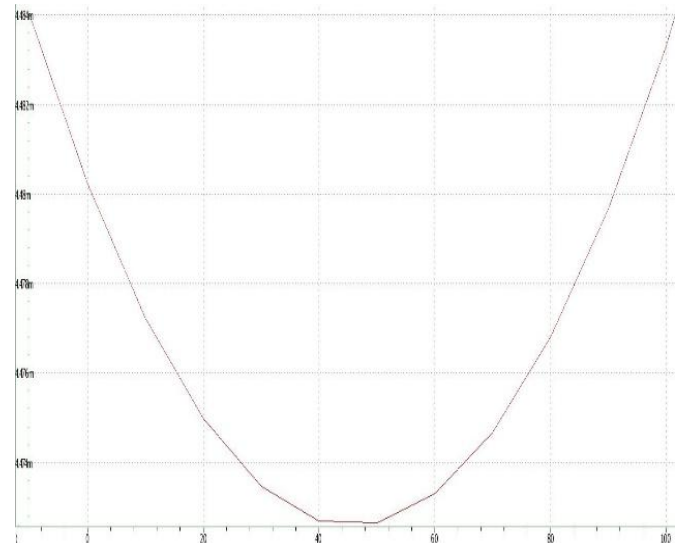

Fig. 9. The temperature coefficient of output current in loading resistance of $100 \Omega$.

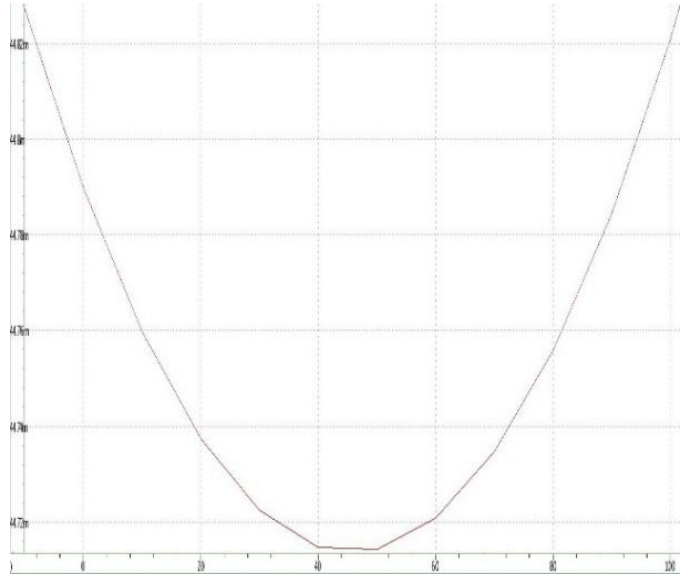

Fig. 10. The temperature coefficient of output current in loading resistance of $1 \mathrm{k} \Omega$.

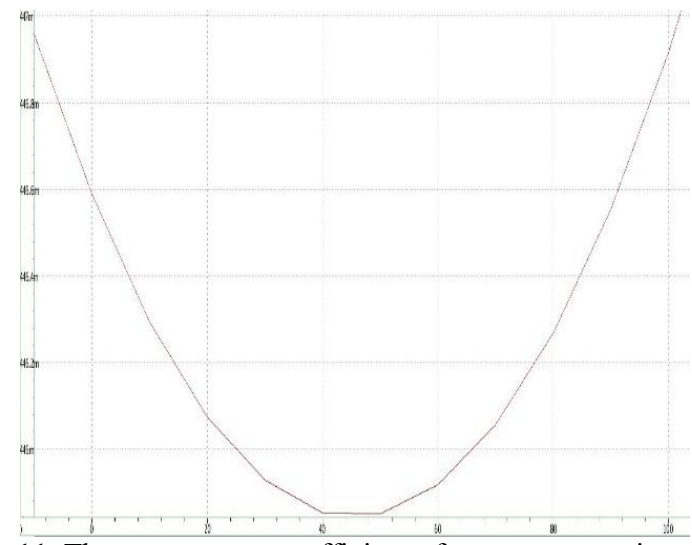

Fig. 11. The temperature coefficient of output current in loading resistance of $10 \mathrm{k} \Omega$

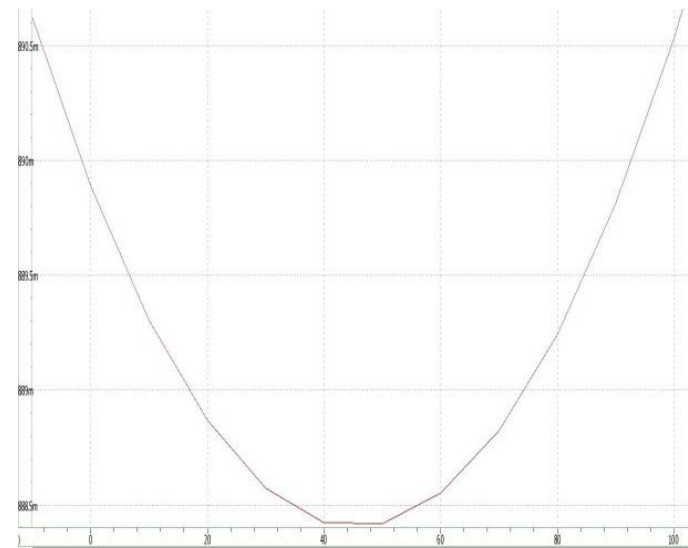

Fig. 12. The temperature coefficient of output current in loading resistance of $20 \mathrm{k} \Omega$.

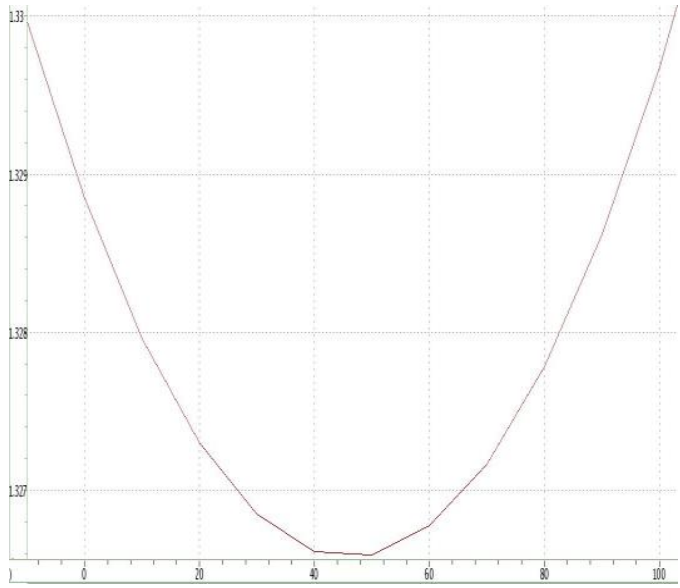

Fig. 13. The temperature coefficient of output current in loading resistance of $30 \mathrm{k} \Omega$. 


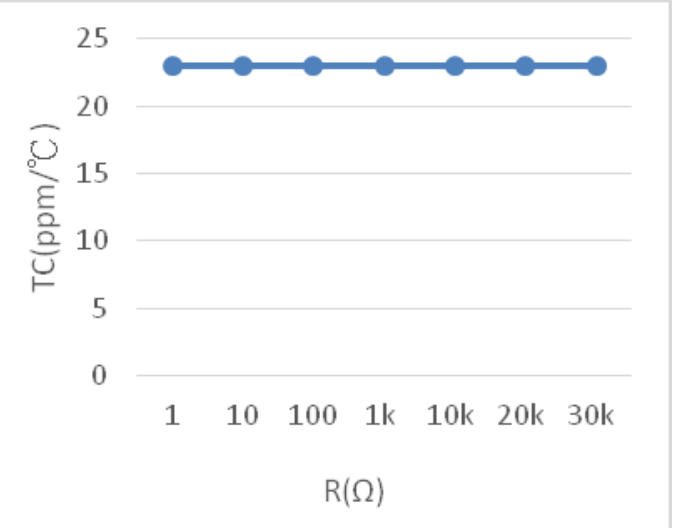

Fig. 14. The corresponding TC value under various resistance loadings.

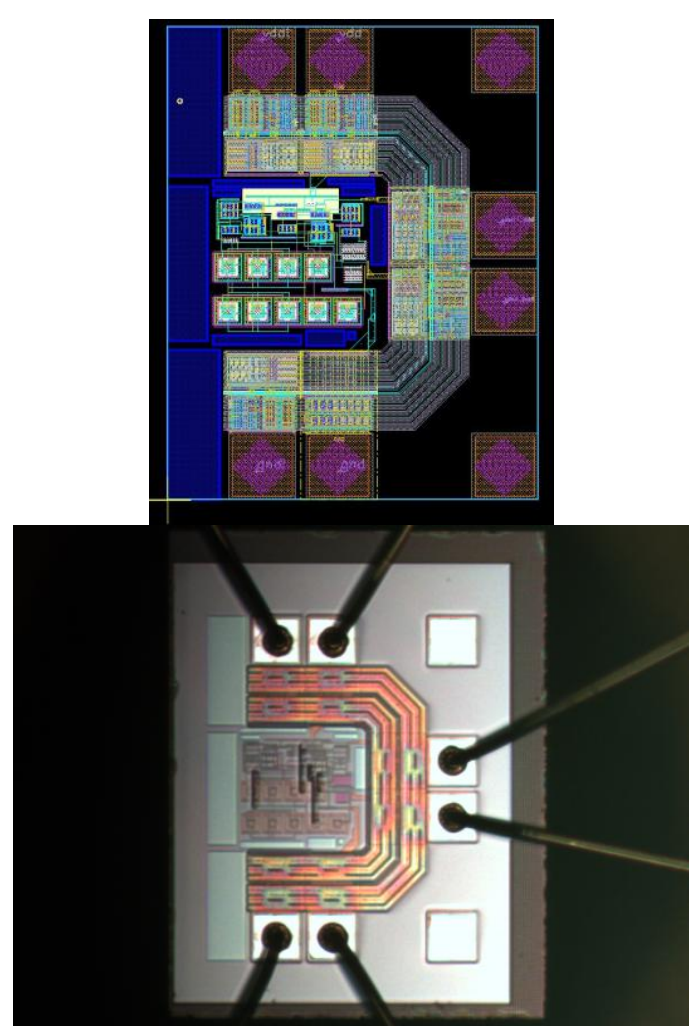

Fig. 15. The layout diagram (top) and micro photo (bottom) of the resembled bandgap reference circuit

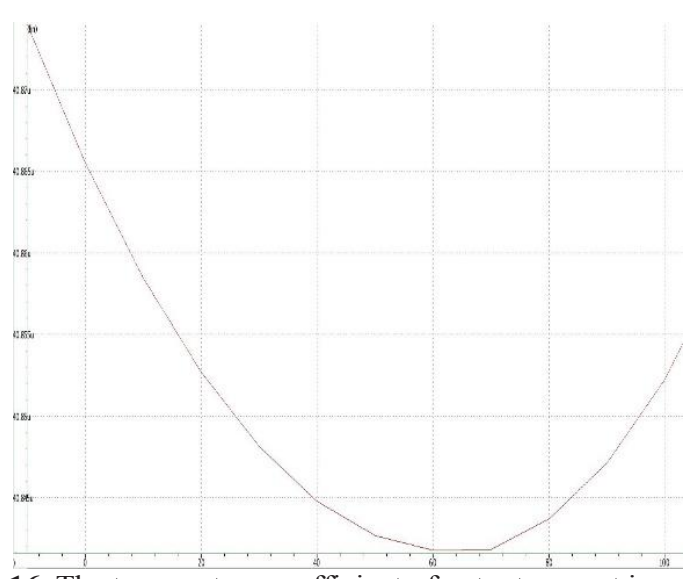

Fig. 16. The temperature coefficient of output current in loading resistance of $1 \Omega$ (by post-layout simulation).

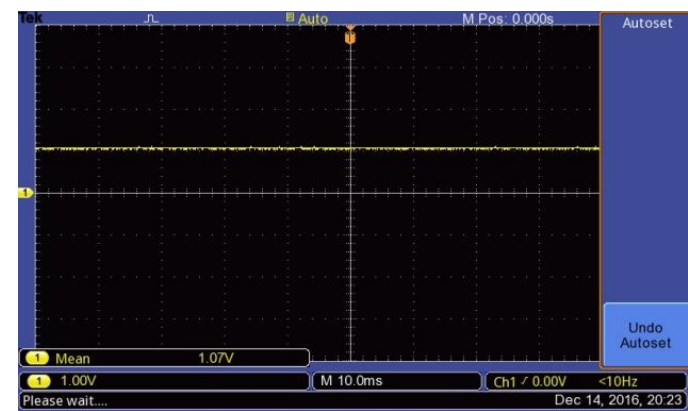

(a)

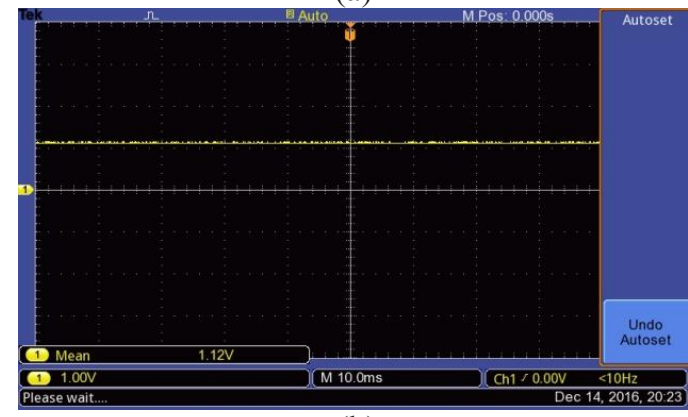

(b)

Fig. 17. The output voltage of the experimental chip for (a) 3$\mathrm{V}$ and (b) 5-V supply voltage respectively.

The characteristics of the proposed circuit summarize and list in Table 1. The characteristics are also compared with reference [1]. The proposed has advantages of low complexity, less chip area, and wide range of output voltage.

Table 1. The characteristics summary and comparison

\begin{tabular}{|c|c|c|}
\hline Characteristics & {$[\mathbf{1}]$} & This work \\
\hline Process & CMOS $0.35 \mu \mathrm{m}$ & CMOS $0.35 \mu \mathrm{m}$ \\
\hline $\begin{array}{c}\text { Operational } \\
\text { Amplifier Required }\end{array}$ & $\begin{array}{c}\text { Need Two } \\
\text { OPAs }\end{array}$ & None \\
\hline Power supply (V) & 0.5 & 3 \\
\hline $\begin{array}{c}\text { Temperature } \\
\left.\text { coefficient (ppm/ }{ }^{\circ} \mathrm{C}\right)\end{array}$ & 13 & 26 (simulation) \\
\hline $\begin{array}{c}\text { Temperature range } \\
\left({ }^{\circ} \mathrm{C}\right)\end{array}$ & $-25-125$ & $-10-100$ \\
\hline $\begin{array}{c}\text { No. of Transistor } \\
\text { Circuit Complexity }\end{array}$ & 23 & $11 \mathrm{MOS}+2 \mathrm{BJT}$ \\
\hline
\end{tabular}

\section{Conclusions}

In contrast to conventional bandgap reference, the ratio of $R_{L}$ and $R_{1}$ is almost constant value to fully eliminate the temperature effect. The output level of the bandgap reference in conventional design is always constant. In this work, we try to generate the current with positive temperature coefficient and a counterpart current with negative temperature coefficient. The two current then are summed at output terminal to cancel the temperature effect of each other. In addition, the output level will be adjustable by altered the loading resistance. 
In this design, the complicated design for OPAs can be neglected to reduce the overall circuit complexity. By simulation, the TC was inspected for the loading of $1 \Omega$, $10 \Omega, 100 \Omega, 1 \mathrm{k} \Omega, 10 \mathrm{k} \Omega, 20 \mathrm{k} \Omega$, and $30 \mathrm{k} \Omega$. The TC will be kept around $23 \mathrm{ppm} /{ }^{\circ} \mathrm{C}$ when temperature is varied from $-10{ }^{\circ} \mathrm{C}$ to $100{ }^{\circ} \mathrm{C}$. Although the $\mathrm{TC}$ is not superior to other designs have been published in open literature which range of $10-15 \mathrm{ppm} /{ }^{\circ} \mathrm{C}$, the chip area and chip design effort are both great reduced.

Acknowledgments: This work was funding part supported by the Ministry of Science and Technology Project (MOST 105-2221-E-167-022), and EDA tools support, experimental CMOS processes and chip fabricated, from the National Chip Implementation Center (CIC) and Taiwan Semiconductor Manufactory Corp. (tsmc).

Author Contributions: H.-P. Chan and Y.-C. Hung conceived and designed this study after co-discussion; H.-P. Chan performed CAD tool simulations and the experiments chip measured; Y.-C. Hung analyzed the data and wrote/organized the paper.

\section{References}

1. J. Sheng, Z. Chen, and B. Shi, "A 1 V supply area effective CMOS bandgap reference," Proceedings of the 5th International Conference on ASIC, 1, pp. 619-622. (2003)

2. J. Chen, and B. Shi, "1 V CMOS current reference with $50 \mathrm{ppm} /{ }^{\circ} \mathrm{C}$ temperature coefficient," Electronics Letters, 39, no. 2, pp. 209-210. (2003)

3. H. Banba, H. Shiga, A. Umezawa, T. Tanzawa, S. Atsumi, and K. Sakui, "A CMOS bandgap reference circuit with sub-1-V operation," IEEE Journal of Solid-State Circuits, 34, pp. 670-674. (1999)

4. H.-M. Chen, C.-L. Huang, R. C. Chang, "A new temperature-compensated CMOS bandgap reference circuit for portable applications," IEEE International Symposium on Circuits and Systems, pp. 21-24, Greece. (2006)

5. J. H. Li, X. B. Zhang, M. Y. Yu, and L. Han,"A 10 $\mathrm{ppm} /{ }^{\circ} \mathrm{C} \quad 1.8 \mathrm{~V}$ piecewise curvature-corrected bandgap reference in $0.5 \mathrm{um}$ cmos," IEEE Microelectronics \& Electronics, pp. 416-419. (2009)

6. M. D. Ker, and J. S. Chen, "New curvaturecompensated technique for CMOS bandgap reference with sub-1-V operation," IEEE Trans on Circuits and Systems II, 53, no. 8, pp. 667-671. (2006)

7. H. J. Oguey, D. Aebischer, "CMOS current reference without resistor", IEEE Journal of SolidState Circuits, 32, no.7, pp. 1132-1135. (1997)

8. C. Azcona, B. Calvo, S. Celma, N. Medrano, M. T. Sanz, "Precision CMOS current reference with process and temperature compensation," IEEE International Symposium on Circuits and Systems, pp. 910-913. (2014)
9. P. E. Allen,"CMOS analog circuit design", Oxford University Press, New York, 2002

10. B. Razavi, "Design of analog CMOS integrated circuit”, McGRAW-HILL. (2001) 